\title{
Viral load and disease severity in COVID-19
}

\author{
Rahul Dnyaneshwar Pawar ${ }^{1,2} \odot$ - Lakshman Balaji ${ }^{2} \cdot$ Shivani Mehta ${ }^{2} \cdot$ Andrew Cole $^{2} \cdot$ Xiaowen Liu $^{2}$. \\ Natia Peradze ${ }^{2}$. Anne Victoria Grossestreuer ${ }^{2} \cdot$ Mahmoud Salah Issa $^{2} \cdot$ Parth Patel $^{2} \cdot$ James Edward Kirby $^{4}$. \\ Christopher Francis Rowley ${ }^{5} \cdot$ Katherine Margaret Berg ${ }^{2,3} \cdot$ Ari Moskowitz $^{2,3} \cdot$ Michael William Donnino $^{2,3}$
}

Received: 28 March 2021 / Accepted: 3 June 2021 / Published online: 16 June 2021

(C) Società Italiana di Medicina Interna (SIMI) 2021

\begin{abstract}
The relationship between COVID-19 severity and viral load is unknown. Our objective was to assess the association between viral load and disease severity in COVID-19. In this single center observational study of adults with laboratory confirmed SARS-CoV-2, the first positive in-hospital nasopharyngeal swab was used to calculate the $\log 10 \mathrm{copies} / \mathrm{ml}[\log 10$ copy number $(\mathrm{CN})$ ] of SARS-CoV-2. Four categories based on level of care and modified sequential organ failure assessment score (mSOFA) at time of swab were determined. Median $\log 10 \mathrm{CN}$ was compared between different levels of care and mSOFA quartiles. Median $\log 10 \mathrm{CN}$ was compared in patients who did and did not receive influenza vaccine, and the correlation between $\log 10 \mathrm{CN}$ and D-dimer was examined. We found that of 396 patients, $54.3 \%$ were male, and $25 \%$ had no major comorbidity. Hospital mortality was 15.7\%. Median mSOFA was 2 (IQR 0-3). Median log 10CN was 5.5 (IQR 3.3-8.0). Median $\log 10 \mathrm{CN}$ was highest in non-intubated ICU patients [6.4 (IQR 4.4-8.1)] and lowest in intubated ICU patients [3.6 (IQR 2.6-6.9)] ( $p$ value $<0.01$ ). In adjusted analyses, this difference remained significant [mean difference 1.16 (95\% CI 0.18-2.14)]. There was no significant difference in $\log 10 \mathrm{CN}$ between other groups in the remaining pairwise comparisons. There was no association between median $\log 10 \mathrm{CN}$ and mSOFA in either unadjusted or adjusted analyses or between median $\log 10 \mathrm{CN}$ in patients with and without influenza immunization. There was no correlation between $\log 10 \mathrm{CN}$ and D-dimer. We conclude, in our cohort, we did not find a clear association between viral load and disease severity in COVID-19 patients. Though viral load was higher in non-intubated ICU patients than in intubated ICU patients there were no other significant differences in viral load by disease severity.
\end{abstract}

Keywords COVID-19 · Coronavirus · SARS-CoV-2 $\cdot$ Viral load $\cdot$ RT-PCR $\cdot$ Organ dysfunction score

\section{Introduction}

Rahul Dnyaneshwar Pawar

rpawar@bidmc.harvard.edu

1 Division of Hospital Medicine, Department of Medicine, Beth Israel Deaconess Medical Center, Harvard Medical School, 1 Deaconess Road, Boston, MA 02215, USA

2 Department of Emergency Medicine, Center for Resuscitation Science, Beth Israel Deaconess Medical Center, Harvard Medical School, Boston, MA, USA

3 Division of Pulmonary, Critical Care and Sleep Medicine, Department of Medicine, Beth Israel Deaconess Medical Center, Harvard Medical School, Boston, MA, USA

4 Department of Pathology, Beth Israel Deaconess Medical Center, Harvard Medical School, Boston, MA, USA

5 Division of Infectious Disease, Department of Medicine, Beth Israel Deaconess Medical Center, Harvard Medical School, Boston, MA, USA
COVID-19, the illness caused by the severe acute respiratory syndrome coronavirus-2 (SARS-CoV-2), was first reported in December 2019 [1] and was declared a pandemic by the World Health Organization in March 2020. Although the majority of those infected will not become severely ill, in those requiring hospitalization COVID-19 is characterized by pneumonia and hypoxemia. This can further lead to Acute Respiratory Distress Syndrome (ARDS) and respiratory failure requiring invasive mechanical ventilation. Early data from small studies based in China suggested that patients with higher baseline viral loads were more likely to have severe COVID-19 disease [2-4]. However, subsequent studies have reported contrasting results, resulting in a lack of clarity on the relationship between viral load and disease severity in this illness [5-7]. 
Early indicators of disease severity could help inform which treatments, such as antivirals, could be effective. Such indicators would also be helpful in determining the likelihood a patient will require escalation of the level of care [e.g. admission to an intensive care unit (ICU)]. In addition, as increasing viral load is associated with an increased transmissibility of COVID-19 [8], if viral load were associated with disease severity, this could help guide policies on infection control. Based on the finding of higher viral load in intubated patients in one study [9], the Centers for Disease Control (CDC) modified their recommendation to consider disease severity before removing isolation precautions at day 10 of a patient's illness [10]. However, currently the relationship between viral load and disease severity in COVID-19 is not well-established.

Physicians and researchers have compared COVID-19 to influenza [11-13] possibly because of the general public's better understanding of the flu. In addition, there is similarity in structure between coronavirus and influenza [14, 15]. Due to the similarity in structure and cross reactivity in immunity between coronavirus and influenza, influenza vaccination providing some protection against COVID-19 has been suggested [16].

To help address the knowledge gap of the relationship between viral load and COVID-19 disease severity, we undertook the following study to compare the viral load at hospital presentation in patients with COVID-19 of different disease severities. We hypothesized that the viral load will be higher in more severe COVID-19 disease and also compared viral load in patients with and without influenza vaccination.

\section{Methods}

\section{Study design}

This is a single center observational cohort study of adult ( $\geq 18$ years) COVID-19 patients who presented either in the ED or were directly admitted to the Medical/Surgical Unit or ICU, with their first positive SARS-CoV-2 nasopharyngeal swab conducted at our institution. Patients admitted from March 1 until April 30, 2020, were included as this period corresponds to the beginning of the initial peak of COVID19 cases in Boston. The Institutional Review Board at Beth Israel Deaconess Medical Center approved this study.

\section{Sample collection and sampling methodology}

The SARS-CoV-2 positive nasopharyngeal swabs which were obtained from the patients presenting to the hospital were used to calculate viral load [represented as $\log 10$ copies/ml i.e. $\log 10 \mathrm{CN}$ (Copy Number)]. Nasopharyngeal swabs of the patients were tested for SARS-CoV-2 using Aldatu PANDAA qDx ${ }^{\mathrm{TM}}$ SARS-CoV-2 Reagents or the Abbott RealTime SARS-CoV-2 assay on the Abbott m2000 System. Cycle threshold (CT) value is a semi-quantitative value of viral genetic material [17]. It is inversely proportional to viral load and is being used in COVID-19 studies as a surrogate of viral load [2-4]. The Abbott RealTime assay provides a $\mathrm{CT}$ calculation called fractional cycle number [18]. We used the $\Delta \Delta \mathrm{CT}$ method ( $\Delta \mathrm{CT}$ for the target sample $-\Delta \mathrm{CT}$ for the reference positive sample) to calculate the copy number of SARS-CoV-2 in each sample. $\Delta \mathrm{CT}$ for each sample was calculated as CT (SARS-CoV-2) - CT (internal control). The fold change for each sample compared to the positive control (1000 copies) was calculated as $2^{(-\Delta \Delta C T)}$. The copy number of SARS-CoV-2 for each sample is calculated as $1000 \mathrm{X}\left[2^{(-\Delta \Delta \mathrm{CT})}\right] \cdot \log 10$ copy number for each sample were used as viral load.

\section{Study patients, data abstraction and handling of missing data}

COVID-19 positive patients were identified using International Classification of Disease-10 (ICD-10) codes (B342, B972, B9721, B9729, J1281, U071). From this cohort, only in-house laboratory-confirmed COVID-19 cases were included in this study. In patients with multiple tests, only the first positive swab was used. Laboratory confirmed COVID-19 patients missed by the above method were found by direct daily abstraction of positive CT values by a trained laboratory technician and were manually included in the study population. Existing inpatients who developed COVID-19 symptoms and later tested positive for the virus were labeled as nosocomial COVID-19 and excluded from this study (see table $\mathrm{S} 1$ for definitions and calculations). Patients for whom the internal control was not detected during polymerase chain reaction analysis were excluded from the study.

Study data were obtained from the patient's electronic medical record (EMR) and reviewed by trained research assistants and physicians. This data included patient demographics, highest D-dimer, time of swab and patient location at the time of swab, duration of hospital and ICU admission, intubation status, disposition and self-reported information on patient's influenza immunization status for the current flu season (beginning from Fall 2019). In addition, vital signs and laboratory findings pertinent to modified sequential organ failure assessment (mSOFA) score (excluding the neurologic subscore) calculation were obtained, if available within $24 \mathrm{~h}$ (before or after) of the positive SARS-CoV-2 result. Missing mSOFA subscore variables were imputed as normal. SOFA score calculations were done based on our previous work [19]. 


\section{Outcomes}

To categorize severity of disease, patients were divided into four groups based on their highest level of care in the $12 \mathrm{~h}$ following nasopharyngeal swab collection. Categories included: (1) ICU and intubated, (2) ICU and not intubated, (3) Medical/Surgical floor, or (4) ED discharge. Patients who stayed in the ED for more than $24 \mathrm{~h}$ were considered admitted and placed in the Medical/Surgical floor category.

SOFA score is a commonly used scoring system for predicting disease severity [20]. The data on neurologic SOFA subscore was not available in EMR especially for the Medical/Surgical and ED patients, and hence the mSOFA score, which excludes the neurologic component and has been used commonly [21-23], was used. In addition, we evaluated the correlation between viral load and D-dimer, which has been shown to be associated with disease severity [24-26]. We excluded ED discharge patients for this analysis as D-dimer was not consistently measured in this population.

Primary outcome: The primary outcome was the difference in viral load by the four pre-defined groups of level of care. Secondary outcomes: Secondary outcomes included the association of viral load with the mSOFA score; the difference in viral load in patients who did and did not receive influenza vaccination; and correlation of viral load with highest D-dimer.

\section{Statistical analysis}

Descriptive statistics are reported as means with standard deviations, medians with interquartile ranges, or counts with frequencies, depending on the type and distribution of data. For continuous outcomes, comparison amongst groups were made using Wilcoxon rank-sum tests or Kruskal-Wallis tests, based on the number of groups being compared. If the overall Kruskal-Wallis test had a $p$ value $<0.05$, comparisons were made using Dunn's test for nonparametric pairwise multiple comparisons. The mSOFA was divided into four quartiles for comparison based on the distribution of data (score $0=$ quartile 1 , score $1=$ quartile 2 , score $2-3=$ quartile 3 and score $4-11=$ quartile 4 ). To adjust for age, sex and having no major comorbidity, multivariate linear regression was used to compare viral load in patients based on their location at the time of swab, and based on their mSOFA scores (as a continuous predictor). The correlation between viral load and highest D-dimer was evaluated using Spearman's rank correlation coefficient.

To eliminate any discrepancies caused by combining the estimates from two different assays, a sensitivity analysis was performed by limiting the analyses to the $85.9 \%$ of patients tested using the Abbott RealTime SARS-CoV-2 test.
All statistical analyses will be performed using Stata version 16 (StataCorp, College Station, TX). A two-sided $p$ value $<0.05$ will be considered statistically significant.

\section{Results}

Information on viral load was present in 437 patients. In 41 patients $(8.6 \%)$, the internal control failed and $\log 10 \mathrm{CN}$ values were not able to be calculated with internal control correction as the internal control failed. These 41 patients were excluded from further analyses, leaving a total of 396 patients included in the study (Table 1, Fig. 1).

\section{Descriptive statistics}

Of the 396 patients, 215 (54.3\%) were male, 146 (36.9\%) were Caucasian, and 136 (34.3\%) were African-American. No major comorbidity was seen in $99(25.0 \%)$ patients. The median mSOFA score for the population was 2 (IQR 0-3) with median mSOFA of 0 (IQR $0-0$ ) in the ED discharge group and median mSOFA of 6 (IQR 4-7) in the intubated ICU group. Hospital mortality in the cohort was $15.7 \%$. In the 270 patients with influenza vaccination information, 152 $(56.3 \%)$ received the influenza vaccine.

\section{Viral load by disease severity}

Median viral load was 5.5 (IQR 3.3-8.0). Median viral load was highest in non-intubated ICU patients [6.4 (IQR 4.4-8.1)] and lowest in intubated ICU patients [3.6 (IQR 2.6-6.9)]. This difference was statistically significant. Median viral load was 5.6 (IQR 3.2, 8.1) in Medical/Surgical floor patients and 4.9 (IQR 3.8, 7.4) in ED discharge patients (Fig. 2). There was no statistically significant difference between any of the other groups ( $p$ value $\geq 0.05$ ) (Table 2). There was also no statistically significant association between median viral load and quantile of mSOFA score ( $p$ value 0.20 ) (Table 3). No correlation was seen between viral load and highest D-dimer (Spearman's rho $0.02, p$ value 0.73 ).

\section{Adjusted analyses}

In the adjusted model controlling for age, sex, and having no major comorbidities, viral load was significantly higher in non-intubated ICU compared to intubated ICU patients with mean difference of 1.16 (95\% CI $0.18-2.14$ ). No difference was observed comparing intubated ICU patients to Medical/Surgical floor patients or to ED discharge patients. After adjusting for the same covariates as above, there was no statistically significant association between 
Table 1 Patient characteristics

\begin{tabular}{|c|c|c|c|c|c|}
\hline & $\begin{array}{l}\text { Total } \\
N=396(100.0 \%)\end{array}$ & $\begin{array}{l}\text { Intubated ICU } \\
N=47(11.9 \%)\end{array}$ & $\begin{array}{l}\text { Non-intubated ICU } \\
N=75(18.9 \%)\end{array}$ & $\begin{array}{l}\text { Medical/surgical } \\
N=228(57.6 \%)\end{array}$ & $\begin{array}{l}\text { ED discharge } \\
N=46(11.6 \%)\end{array}$ \\
\hline \multicolumn{6}{|l|}{ Patient demographics } \\
\hline Male $n(\%)$ & $215(54.3 \%)$ & $28(59.6 \%)$ & $42(56.0 \%)$ & $118(51.8 \%)$ & $27(58.7 \%)$ \\
\hline Age, mean (SD) & $64.8(17.0)$ & $59.4(14.5)$ & $72.4(13.2)$ & $65.7(17.2)$ & $53.6(16.8)$ \\
\hline \multicolumn{6}{|l|}{ Race, $n(\%)$} \\
\hline Asian & $18(4.5 \%)$ & $5(10.6 \%)$ & $3(4.0 \%)$ & $7(3.1 \%)$ & $3(6.5 \%)$ \\
\hline African-American & $136(34.3 \%)$ & $8(17.0 \%)$ & $21(28.0 \%)$ & $88(38.6 \%)$ & $19(41.3 \%)$ \\
\hline Other & $45(11.4 \%)$ & $6(12.8 \%)$ & $7(9.3 \%)$ & $25(11.0 \%)$ & $7(15.2 \%)$ \\
\hline $\begin{array}{l}\text { Unknown/not } \\
\text { reported }\end{array}$ & $51(12.9 \%)$ & $15(31.9 \%)$ & $8(10.7 \%)$ & $22(9.6 \%)$ & $6(13.0 \%)$ \\
\hline Caucasian & $146(36.9 \%)$ & $13(27.7 \%)$ & $36(48.0 \%)$ & $86(37.7 \%)$ & $11(23.9 \%)$ \\
\hline $\mathrm{BMI}^{\mathrm{a}}$, median (IQR) & $29.9(26.1-34.2)$ & $31.5(28.8-37.5)$ & $28.9(25.5-32.7)$ & $29.9(25.4-34.2)$ & $34.4(18.3-38.6)$ \\
\hline Missing BMI (n \%) & $98(24.8 \%)$ & $3(6.4 \%)$ & $12(16.0 \%)$ & $40(17.5 \%)$ & $43(93.5 \%)$ \\
\hline \multicolumn{6}{|c|}{ Past medical history, $n(\%)$} \\
\hline $\begin{array}{l}\text { No major comorbidi- } \\
\text { ties }\end{array}$ & $99(25.0 \%)$ & $17(36.2 \%)$ & $10(13.3 \%)$ & $51(22.4 \%)$ & $21(45.7 \%)$ \\
\hline $\mathrm{CAD}^{\mathrm{b}}$ & $52(13.1 \%)$ & $6(12.8 \%)$ & $8(10.7 \%)$ & $36(15.8 \%)$ & $2(4.3 \%)$ \\
\hline $\mathrm{CHF}^{\mathrm{c}}$ & $47(11.9 \%)$ & $4(8.5 \%)$ & $14(18.7 \%)$ & $28(12.3 \%)$ & $1(2.2 \%)$ \\
\hline Cancer & $60(15.2 \%)$ & $4(8.5 \%)$ & $14(18.7 \%)$ & $40(17.5 \%)$ & $2(4.3 \%)$ \\
\hline $\operatorname{COPD}^{\mathrm{d}}$ & $37(9.3 \%)$ & $5(10.6 \%)$ & $13(17.3 \%)$ & $17(7.5 \%)$ & $2(4.3 \%)$ \\
\hline $\begin{array}{l}\text { Dementia/Alzhei- } \\
\text { mer's }\end{array}$ & $44(11.1 \%)$ & $3(6.4 \%)$ & $11(14.7 \%)$ & $29(12.7 \%)$ & $1(2.2 \%)$ \\
\hline Diabetes & $140(35.4 \%)$ & $16(34.0 \%)$ & $29(38.7 \%)$ & $87(38.2 \%)$ & $8(17.4 \%)$ \\
\hline Renal disease & $75(18.9 \%)$ & $3(6.4 \%)$ & $19(25.3 \%)$ & $52(22.8 \%)$ & $1(2.2 \%)$ \\
\hline Liver disease & $17(4.3 \%)$ & $2(4.3 \%)$ & $3(4.0 \%)$ & $10(4.4 \%)$ & $2(4.3 \%)$ \\
\hline Arrhythmia & $50(12.6 \%)$ & $3(6.4 \%)$ & $14(18.7 \%)$ & $31(13.6 \%)$ & $2(4.3 \%)$ \\
\hline Alcohol use disorder & $23(5.8 \%)$ & $5(10.6 \%)$ & $4(5.3 \%)$ & $12(5.3 \%)$ & $2(4.3 \%)$ \\
\hline Stroke & $32(8.1 \%)$ & $3(6.4 \%)$ & $8(10.7 \%)$ & $20(8.8 \%)$ & $1(2.2 \%)$ \\
\hline Transplant & $4(1.0 \%)$ & $0(0.0 \%)$ & $0(0.0 \%)$ & $4(1.8 \%)$ & $0(0.0 \%)$ \\
\hline HIV/AIDS ${ }^{\mathrm{e}}$ & $4(1.0 \%)$ & $0(0.0 \%)$ & $1(1.3 \%)$ & $2(0.9 \%)$ & $1(2.2 \%)$ \\
\hline Asthma & $51(12.9 \%)$ & $3(6.4 \%)$ & $9(12.0 \%)$ & $27(11.8 \%)$ & $12(26.1 \%)$ \\
\hline $\begin{array}{l}\text { Morbid obesity } \\
\quad(\mathrm{BMI}>40)\end{array}$ & $34(8.7 \%)$ & $7(15.2 \%)$ & $4(5.3 \%)$ & $23(10.2 \%)$ & $0(0.0 \%)$ \\
\hline \multicolumn{6}{|l|}{ SOFA, median (IQR) } \\
\hline $\begin{array}{l}\text { Modified total SOFA } \\
\text { score }\end{array}$ & $2(0-3)$ & $6(4-7)$ & $2(1-4)$ & $1(0-2)$ & $0(0-0)$ \\
\hline Respiratory SOFA & $0(0-1)$ & $3(2-4)$ & $1(0-2)$ & $0(0-1)$ & $0(0-0)$ \\
\hline Cardiac SOFA & $0(0-0)$ & $0(0-3)$ & $0(0-0)$ & $0(0-0)$ & $0(0-0)$ \\
\hline Coagulation SOFA & $0(0-0)$ & $0(0-1)$ & $0(0-0)$ & $0(0-0)$ & $0(0-0)$ \\
\hline Liver SOFA & $0(0-0)$ & $0(0-0)$ & $0(0-0)$ & $0(0-0)$ & $0(0-0)$ \\
\hline Renal SOFA & $0(0-1)$ & $0(0-1)$ & $1(0-2)$ & $0(0-1)$ & $0(0-0)$ \\
\hline \multicolumn{6}{|c|}{ Lab values, median (IQR) } \\
\hline $\begin{array}{l}\text { Viral load } \\
(\log 10 \mathrm{CN}) \text {, median } \\
(\mathrm{IQR})\end{array}$ & $5.5(3.3,8.0)$ & $3.6(2.6,6.9)$ & $6.4(4.4,8.1)$ & $5.7(3.2,8.1)$ & $4.9(3.8,7.4)$ \\
\hline $\begin{array}{l}\text { Highest D-dimer, } \\
\text { median (IQR) }\end{array}$ & $1504.0(743.0-4416.0)$ & $\begin{array}{l}4126.5(2063.0- \\
15,764.0)\end{array}$ & $1640.0(938.0-7134.0)$ & $1105.0(672.0-2102.0)$ & $313.0(304.0-886.0)$ \\
\hline $\begin{array}{l}\text { Missing D-dimer, } \\
n(\%)\end{array}$ & $79(20.0 \%)$ & $1(2.1 \%)$ & $8(10.7 \%)$ & $27(11.9 \%)$ & $43(93.5 \%)$ \\
\hline \multicolumn{6}{|l|}{ Influenza immunization } \\
\hline $\begin{array}{l}\text { Influenza immuniza- } \\
\quad \text { tion, } n(\%)\end{array}$ & $152(56.3 \%)$ & $8(36.4 \%)$ & $25(55.6 \%)$ & $101(61.6 \%)$ & $18(46.2 \%)$ \\
\hline
\end{tabular}


Table 1 (continued)

\begin{tabular}{llllll}
\hline & Total & Intubated ICU & Non-intubated ICU & Medical/surgical & ED discharge \\
$N=396(100.0 \%)$ & $N=47(11.9 \%)$ & $N=75(18.9 \%)$ & $N=228(57.6 \%)$ & $N=46(11.6 \%)$ \\
\hline $\begin{array}{c}\text { Missing influenza } \\
\text { immunization, } \\
n(\%)\end{array}$ & $126(31.8 \%)$ & $25(53.2 \%)$ & $30(40.0 \%)$ & $64(28.1 \%)$ & $7(15.2 \%)$ \\
$\begin{array}{l}\text { Mortality } \\
n(\%)\end{array}$ & & & & \\
\hline
\end{tabular}

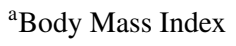

${ }^{\mathrm{b}}$ Coronary artery disease

${ }^{\mathrm{c}}$ Congestive heart failure

${ }^{\mathrm{d}}$ Chronic obstructive pulmonary disease

${ }^{\mathrm{e}}$ Human Immunodeficiency Virus/Acquired Immunodeficiency Syndrome

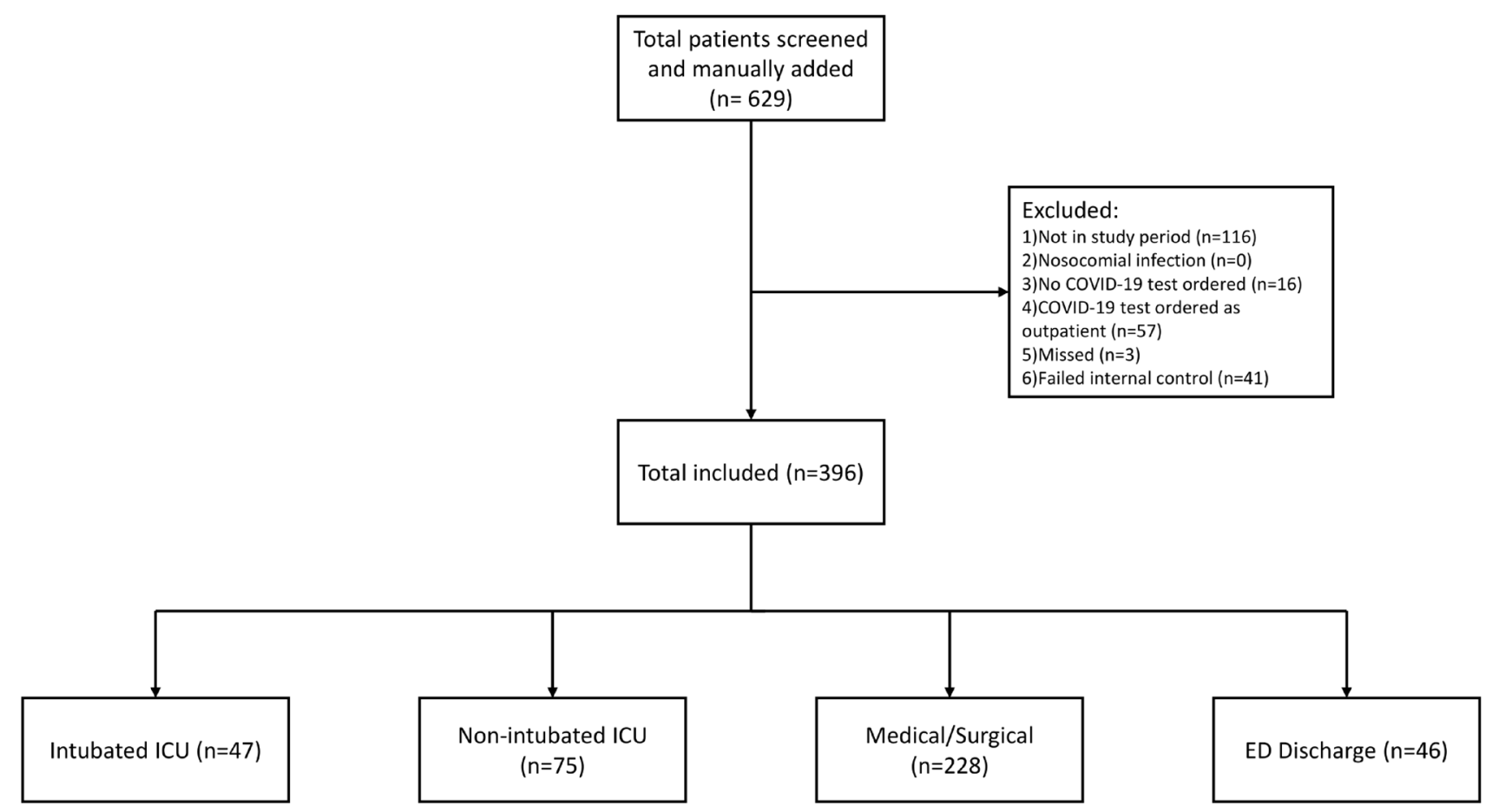

Fig. 1 Consort diagram

viral load and mSOFA score with a mean difference of $0.01(95 \% \mathrm{CI}-0.12$ to 0.13$)$ per unit increase in mSOFA score (Table 3).

\section{Viral load and influenza immunization}

There was no statistically significant difference in median viral load based on influenza immunization status [median $\log 10 \mathrm{CN}$ in immunized patients 5.2 (IQR $3.2,8.0$ ) versus in non-immunized patients 5.2 (IQR 3.3, 8.1); $p$ value 0.78 ] (Table S2).

\section{Sensitivity analyses}

In a sensitivity analysis only including patients whose viral load was obtained using Abbott RealTime SARS-CoV-2 (340 patients), there was no statistically significant difference between viral load in different levels of care in both unadjusted and adjusted analyses. No statistically significant difference was seen comparing viral load to mSOFA in both unadjusted and adjusted analyses, and no differences were seen in viral load based on influenza immunization status. Please see Table S3 for complete details of the sensitivity analysis. 


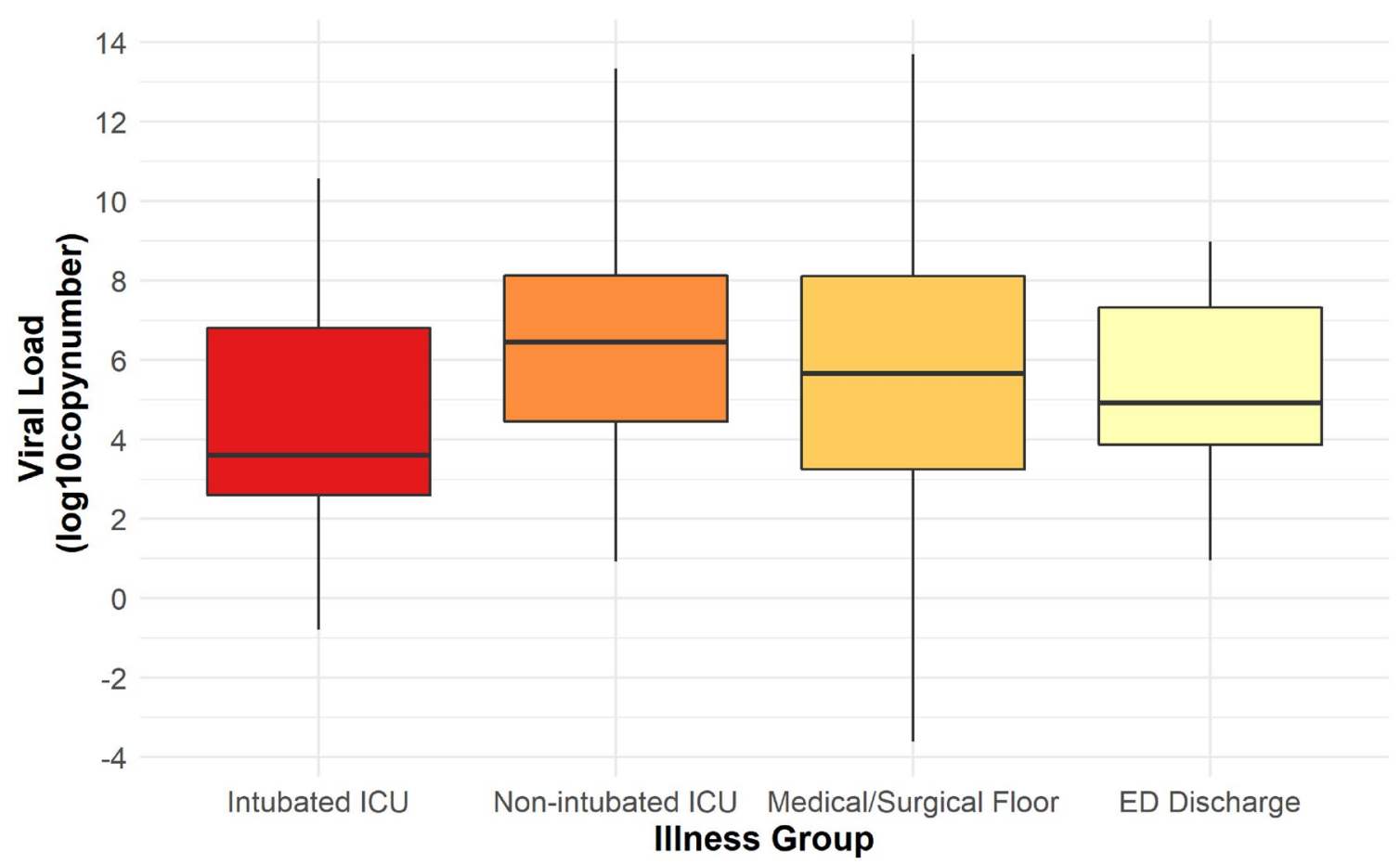

Fig. 2 Viral load in different disease severity

Table 2 Comparison of viral $\operatorname{load}(\log 10 \mathrm{CN})$ in different disease severity

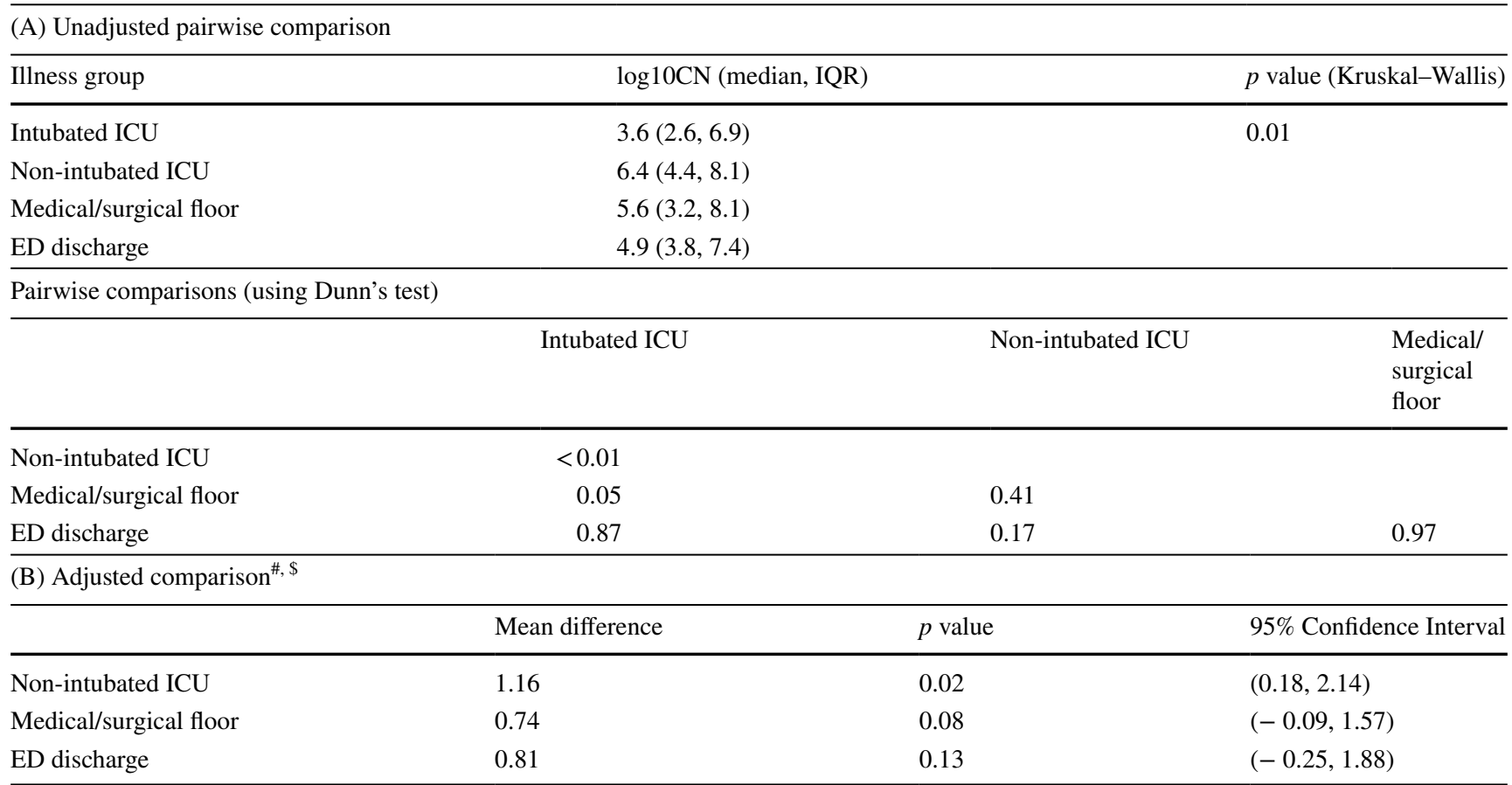

\#Using linear regression with Intubated ICU group as the reference

${ }^{\$}$ Covariates used are age, sex and no major comorbidities 
Table 3 Comparison of viral $\operatorname{load}(\log 10 \mathrm{CN})$ with modified sofa score

\begin{tabular}{|c|c|c|c|}
\hline \multicolumn{4}{|l|}{ (A) Unadjusted comparison } \\
\hline mSOFA quartile & $\log 10 \mathrm{CN}$ (median, IQR) & & $p$ value (Kruskal-Wallis) \\
\hline $1(\mathrm{~m} \mathrm{SOFA}=0)$ & $4.6(3.0,7.6)$ & & 0.20 \\
\hline $2(\mathrm{mSOFA}=1)$ & $5.7(3.4,7.9)$ & & \\
\hline $3(\mathrm{mSOFA}=2-3)$ & $5.7(3.3,8.2)$ & & \\
\hline $4(\mathrm{mSOFA}=4-11)$ & $6.2(3.4,8.0)$ & & \\
\hline \multicolumn{4}{|l|}{ (B) Adjusted comparison ${ }^{\#, \$}$} \\
\hline & Mean difference & $p$ value & $95 \% \mathrm{CI}$ \\
\hline 1 unit increase in mSOFA & 0.01 & 0.92 & $(-0.12,0.13)$ \\
\hline
\end{tabular}

No pairwise comparisons performed as overall Kruskal-Wallis is not significant

\#Using linear regression

${ }^{\$}$ Covariates used are age, sex and no major comorbidities

\section{Discussion}

Our study focuses on the comparison of viral load between different categories of disease severity. We found that the median viral load was higher in non-intubated ICU patients as compared to intubated ICU patients in both unadjusted and adjusted analyses, but there was no difference in viral load between other groups. In addition, there was no association seen between viral load and mSOFA score or between viral load and patient influenza vaccination status. However, when the analyses were restricted to only the $86 \%$ of patients whose viral load was obtained using Abbott RealTime SARS-CoV-2, even the difference between intubated ICU patients and non-intubated ICU patients was no longer significant.

Healthcare professionals, researchers and the lay-public have compared COVID-19 and influenza characteristics $[11-13,27]$. In influenza, studies have found a positive relationship between viral load and disease severity [28-31] but there is conflicting data regarding this relationship in COVID-19 [2, 3, 5-7]. One explanation for this could be that in severe COVID-19 patients, viral pneumonia progresses to acute respiratory distress syndrome (ARDS) [32], which is the main driver of intubation in COVID-19 [12] and presents relatively later in the disease course. Due to the temporal relationship between viral load in COVID-19 and disease progression wherein viral load decreases with duration of the disease [5, 33, 34], by the time COVID-19 patients are intubated, they may be in the latter part of their disease, which could explain their relatively lower viral load.

Barring the intubated ICU group where the viral load was the lowest, the viral load in this study did appear to increase with increasing severity based on levels of care, but there was no statistically significant difference between these groups (Table 2). In addition to comparing the viral load between four categorical disease severity groups, we analyzed the association of the viral load in COVID-19 with a patient's mSOFA score. In our study, the viral load was not associated with the mSOFA, further supporting the lack of a clear association between viral load in COVID-19 patients and disease severity.

Van Kampen et al. [9] reported that intubated COVID-19 patients have higher viral loads and prolonged viral shedding and suggested considering disease severity before removing isolation precautions. Based on this finding, the CDC modified their recommendations and suggested incorporating severity status into the decision to remove isolation precautions [10]. Conventional wisdom suggests that isolation precautions are most necessary during the most severe stages of disease. Our data, however, argues that there is a strong need to maintain isolation precautions during handling of COVID-19 patients irrespective of their disease severity; in fact it might be more important in patients who are not intubated.

There is a hypothesis that prior immunization against influenza provides improved immunity against SARS-CoV-2 [16]; however, in our study population both influenza immunized and non-immunized patients had similar viral load ( $p$ value 0.78 ). Any infection, like COVID-19, induces a cascade of events leading to activation of fibrinolytic system and production of D-dimer [35], and it increases with increasing viral load [35]. In our study, we did not find a correlation between D-dimer and viral load.

Our study results taken together did not show a clear relationship between viral load and disease severity. Though not a focus of this manuscript, other inflammatory and cytokine markers like D-dimer, interleukin, interferon- $\gamma$, TNF- $\alpha$ etc. have shown promise in being associated with COVID-19 disease and disease severity [24, 36].

Our study has the following limitations. First, this is a retrospective study and our result of higher viral load in nonintubated ICU patients compared to intubated ICU patients 
was not statistically significant in sensitivity analyses. Second, our study design did not allow us to gather data on onset and duration of COVID-19 symptoms and hence we were unable to account for disease duration prior to testing. Finally, viral load measurement is dependent on the quality and quantity of the specimen obtained by the nasopharyngeal swab; variation in this could have affected our results. However, due to lack of better, relatively non-invasive and simpler techniques to obtain mucus specimens in COVID-19 patients, this is currently the best available method.

\section{Conclusion}

In our cohort, we did not find a clear association between viral load and disease severity in COVID-19 patients. Viral load was higher in non-intubated ICU patients than in intubated ICU patients though this difference was not seen in the sensitivity analysis. There was no difference in viral load between intubated ICU patients and patients with other levels of care or between patients with disease severity stratified by mSOFA.

Supplementary Information The online version contains supplementary material available at https://doi.org/10.1007/s11739-021-02786-w.

Acknowledgements We would like to thank Annie Cheng for sharing CT correlation data for Abbott and Aldatu assays, and Susan Chin for bioinformatic support. Both are in the Department of Pathology at Beth Israel Deaconess Medical Center, and Francesca Montillo, Department of Emergency Medicine, for the editorial support with the manuscript.

Author contributions RP, XL, AG, KB, AM, MD prepared the manuscripts; RP, SM, AC, NP, MI, PP collected the data; LB, AG analyzed the data; LB prepared figures; MD, JK, CR, RP conceptualized the study. All authors reviewed the manuscript.

Funding Dr. Donnino's effort is supported, in part, by grants from the National Institutes of Health (K24HL127101, R01HL136705, 1R01DK112886, 1R03 AA026093).

Availability of data and materials Raw data were generated at Beth Israel Deaconess Medical Center. Derived data supporting the findings of this study are available on request.

Code availability All code for data cleaning and analysis associated with the current submission is available on request.

\section{Declarations}

Conflict of interest The authors declare that there is no conflict of interest.

Statements on human and animal rights The Institutional Review Board at Beth Israel Deaconess Medical Center approved this study.

Informed consent Patient consent was waived as there was no patient contact.

\section{References}

1. Wang P, Anderson N, Pan Y et al (2020) The SARS-CoV-2 outbreak: diagnosis, infection prevention, and public perception. Clin Chem. https://doi.org/10.1093/clinchem/hvaa080

2. Yu X, Sun S, Shi Y et al (2020) SARS-CoV-2 viral load in sputum correlates with risk of COVID-19 progression. Crit Care 24:170. https://doi.org/10.1186/s13054-020-02893-8

3. Liu Y, Yan L-M, Wan L et al (2020) Viral dynamics in mild and severe cases of COVID-19. Lancet Infect Dis 20:656-657. https:// doi.org/10.1016/S1473-3099(20)30232-2

4. Zheng S, Fan J, Yu F et al (2020) Viral load dynamics and disease severity in patients infected with SARS-CoV-2 in Zhejiang province, China, January-March 2020: retrospective cohort study. BMJ 369:m1443. https://doi.org/10.1136/bmj.m1443

5. Zou L, Ruan F, Huang $M$ et al (2020) SARS-CoV-2 viral load in upper respiratory specimens of infected patients. N Engl J Med 382:1177-1179. https://doi.org/10.1056/NEJMc2001737

6. Zacharioudakis IM, Prasad PJ, Zervou FN et al (2020) Association of SARS-CoV-2 genomic load with COVID-19 patient outcomes. Ann Am Thorac Soc. https://doi.org/10.1513/AnnalsATS. 202008-931RL

7. Argyropoulos KV, Serrano A, Hu J et al (2020) Association of initial viral load in severe acute respiratory syndrome coronavirus 2 (SARS-CoV-2) patients with outcome and symptoms. Am J Pathol 190:1881-1887. https://doi.org/10.1016/j.ajpath.2020.07. 001

8. He X, Lau EHY, Wu P et al (2020) Temporal dynamics in viral shedding and transmissibility of COVID-19. Nat Med 26:672675. https://doi.org/10.1038/s41591-020-0869-5

9. van Kampen JJA, van de Vijver DAMC, Fraaij PLA et al (2020) Shedding of infectious virus in hospitalized patients with coronavirus disease-2019 (COVID-19): duration and key determinants. medRxiv. https://doi.org/10.1101/2020.06.08.20125310

10. Duration of Isolation and Precautions for Adults with COVID-19 I CDC. https://www.cdc.gov/coronavirus/2019-ncov/hcp/durat ion-isolation.html?CDC_AA_refVal=https $\% 3 \mathrm{~A} \% 2 \mathrm{~F} \% 2 \mathrm{Fwww}$. cdc.gov\%2Fcoronavirus\%2F2019-ncov\%2Fcommunity $\% 2$ Fstr ategy-discontinue-isolation.html. Accessed 13 Dec 2020

11. Gjurašin B, Santini M, Krajinović V et al (2020) A retrospective comparison between influenza and COVID-19-associated ARDS in a Croatian tertiary care center. Wien Klin Wochenschr. https:// doi.org/10.1007/s00508-020-01759-x

12. Donnino MW, Moskowitz A, Thompson GS et al (2021) Comparison between patients hospitalized with influenza and COVID-19 at a tertiary care center. J Gen Intern Med 36:1689-1695. https:// doi.org/10.1007/s11606-021-06647-2

13. Is the Coronavirus Worse Than the Flu? - Coronavirus vs. Flu I Health.com. https://www.health.com/condition/infectious-disea ses/coronavirus-worse-than-flu. Accessed 24 Dec 2020

14. Abdella R, Aggarwal M, Okura T et al (2020) Structure of a paramyxovirus polymerase complex reveals a unique methyltransferase-CTD conformation. Proc Natl Acad Sci USA 117:49314941. https://doi.org/10.1073/pnas.1919837117

15. Zeng Q, Langereis MA, van Vliet ALW et al (2008) Structure of coronavirus hemagglutinin-esterase offers insight into corona and influenza virus evolution. Proc Natl Acad Sci USA 105:90659069. https://doi.org/10.1073/pnas.0800502105

16. Salem ML, El-Hennawy D (2020) The possible beneficial adjuvant effect of influenza vaccine to minimize the severity of COVID-19. Med Hypotheses 140:109752. https://doi.org/10. 1016/j.mehy.2020.109752

17. https://assets.publishing.service.gov.uk/government/uploads/system/uploads/attachment_data/file/926410/Understanding_Cycle_ Threshold_Ct_in_SARS-CoV-2_RT-PCR_.pdf. https://assets. 
publishing.service.gov.uk/government/uploads/system/uploads/ attachment_data/file/926410/Understanding_Cycle_Threshold_ Ct_in_SARS-CoV-2_RT-PCR_.pdf. Accessed 16 Dec 2020

18. Shain EB, Clemens JM (2008) A new method for robust quantitative and qualitative analysis of real-time PCR. Nucleic Acids Res 36:e91. https://doi.org/10.1093/nar/gkn408

19. Pawar RD, Shih JA, Balaji L et al (2020) Variation in SOFA (sequential organ failure assessment) score performance in different infectious states. J Intensive Care Med. https://doi.org/10. $1177 / 0885066620944879$

20. Vincent JL, Moreno R, Takala J et al (1996) The SOFA (Sepsisrelated Organ Failure Assessment) score to describe organ dysfunction/failure. Intensive Care Med 22:707-710. https://doi.org/ $10.1007 / \mathrm{s} 001340050156$

21. Gordon AC, Perkins GD, Singer M et al (2016) Levosimendan for the prevention of acute organ dysfunction in sepsis. N Engl J Med 375:1638-1648. https://doi.org/10.1056/NEJMoa1609409

22. Hamano N, Nishi K, Onose A et al (2013) Efficacy of singledose intravenous immunoglobulin administration for severe sepsis and septic shock. J Intensive Care 1:4. https://doi.org/10.1186/ 2052-0492-1-4

23. Andrews PJD, Avenell A, Noble DW et al (2011) Randomised trial of glutamine, selenium, or both, to supplement parenteral nutrition for critically ill patients. BMJ 342:d1542. https://doi.org/10.1136/ bmj.d1542

24. Singhania N, Bansal S, Nimmatoori DP et al (2020) Current overview on hypercoagulability in COVID-19. Am J Cardiovasc Drugs 20:393-403. https://doi.org/10.1007/s40256-020-00431-z

25. Yao Y, Cao J, Wang Q et al (2020) D-dimer as a biomarker for disease severity and mortality in COVID-19 patients: a case control study. J Intensive Care 8:49. https://doi.org/10.1186/ s40560-020-00466-Z

26. Tang N, Bai H, Chen X et al (2020) Anticoagulant treatment is associated with decreased mortality in severe coronavirus disease 2019 patients with coagulopathy. J Thromb Haemost 18:10941099. https://doi.org/10.1111/jth.14817

27. How does the new coronavirus compare with the flu? I Live Science. https://www.livescience.com/new-coronavirus-comparewith-flu.html. Accessed 24 Dec 2020
28. Lee N, Chan PKS, Hui DSC et al (2009) Viral loads and duration of viral shedding in adult patients hospitalized with influenza. J Infect Dis 200:492-500. https://doi.org/10.1086/600383

29. Lee N, Chan PKS, Choi KW et al (2007) Factors associated with early hospital discharge of adult influenza patients. Antivir Ther (Lond) 12:501-508

30. Hayden FG, Fritz R, Lobo MC et al (1998) Local and systemic cytokine responses during experimental human influenza A virus infection. Relation to symptom formation and host defense. J Clin Invest 101:643-649. https://doi.org/10.1172/JCI1355

31. Kaiser L, Fritz RS, Straus SE et al (2001) Symptom pathogenesis during acute influenza: interleukin- 6 and other cytokine responses. J Med Virol 64:262-268. https://doi.org/10.1002/jmv. 1045

32. Gibson PG, Qin L, Puah SH (2020) COVID-19 acute respiratory distress syndrome (ARDS): clinical features and differences from typical pre-COVID-19 ARDS. Med J Aust 213:54-56.e1. https:// doi.org/10.5694/mja2.50674

33. Yu F, Yan L, Wang N et al (2020) Quantitative detection and viral load analysis of SARS-CoV-2 in infected patients. Clin Infect Dis 71:793-798. https://doi.org/10.1093/cid/ciaa345

34. To KK-W, Tsang OT-Y, Leung W-S et al (2020) Temporal profiles of viral load in posterior oropharyngeal saliva samples and serum antibody responses during infection by SARS-CoV-2: an observational cohort study. Lancet Infect Dis 20:565-574. https://doi. org/10.1016/S1473-3099(20)30196-1

35. Srivastava S, Garg I, Bansal A, Kumar B (2020) COVID-19 infection and thrombosis. Clin Chim Acta 510:344-346. https://doi. org/10.1016/j.cca.2020.07.046

36. Costela-Ruiz VJ, Illescas-Montes R, Puerta-Puerta JM et al (2020) SARS-CoV-2 infection: the role of cytokines in COVID-19 disease. Cytokine Growth Factor Rev 54:62-75. https://doi.org/10. 1016/j.cytogfr.2020.06.001

Publisher's Note Springer Nature remains neutral with regard to jurisdictional claims in published maps and institutional affiliations. 